\title{
UM PANORAMA DAS PESQUISAS QUE VERSAM SOBRE O USO DO SMARTPHONE NO ENSINO DE CIÊNCIAS DOS ANOS INICIAIS DA EDUCAÇÃO BÁSICA
}

\author{
Luciano Pavnoski ${ }^{1}$ \\ Marcelo Motta ${ }^{2}$ \\ Tanieli Loss ${ }^{3}$ \\ Thaís Rafaela Hilger ${ }^{4}$
}

RESUMO: O uso de smartphones pode ser direcionado aos meios educacionais, possibilitando processos educativos diferenciados aos Ensino de Ciências. Nessa direção, propomos neste artigo, identificar os achados nas dissertações e teses que utilizam os smartphones para o ensino de Ciências para os Anos Iniciais do Ensino Fundamental voltados a TAS - Teoria da Aprendizagem Significativa. Nesse viés, realizamos uma pesquisa qualitativa investigativa por meio de levantamento de pesquisas que tratam dessa temática. Assim, realizando o levantamento na Biblioteca Digital Brasileira de Teses e Dissertações, em pesquisas de 2018 a 2020, tivemos um retorno de 67 trabalhos que tratavam do uso de tecnologias digitais no Ensino de Ciência no Ensino Fundamental I. Aplicando os critérios de exclusão e inclusão, houve um retorno de apenas duas pesquisas que abordavam nosso objeto de estudo. Observando-as, trouxemos aspectos sobre o uso pedagógico de tal tecnologia a área de Ciências e percebemos, para que haja contribuições nos processos de ensino e de aprendizagem de Ciências, no viés da TAS.

Palavras- Chaves: Ensino de Ciências. Tecnologia Digital. Smartphone. Teoria da Aprendizagem Significativa.

ABSTRACT: The use of smartphones can be directed to educational means, enabling differentiated educational processes to Science Teaching. In this direction, we propose in this article, to identify the findings in the dissertations and theses that use smartphones for the teaching of Science for the Early Years of Elementary School focused on TAS - Theory of Meaningful Learning. In this vein, we conducted a qualitative investigative research by surveying research that addresses this theme. Thus, carrying out the survey in the Brazilian Digital Library of Theses and Dissertations, in surveys from 2018 to 2020, we had a return of 67 works that dealt with the use of digital technologies in Science Education in Elementary School I. Applying the exclusion criteria and inclusion, there was a return of only two studies that addressed our object of study. Observing them, we brought aspects about the pedagogical use of such technology to the Science area and we realized, so that there are contributions in the teaching and learning processes of Sciences, in the bias of TAS.

\footnotetext{
${ }^{1}$ Mestrando do PPGECM - Programa de Pós Graduação em Educação em Ciências e em Matemática da UFPR - Universidade Federal do Paraná. Professor efetivo da Secretaria Municipal de Educação de Cruzeiro do Iguaçu - PR e Boa Esperança do Iguaçu - PR. E-mail: lucianopavnoski@hotmail.com.

${ }^{2}$ Doutor em Ensino de Ciências e Matemática pela Universidade Cruzeiro do Sul; Professor Adjunto da UTFPR.E-mail: marcelomotta@utfpr.edu.br.

${ }^{3}$ Doutoranda no Programa de Pós-Graduação em Formação Científica, Educacional e Tecnológica pela UTFPR; Professora da Secretaria Municipal de Educação de Curitiba. E-mail: tani_loss@hotmail.com.

${ }^{4}$ Professora Post.Doc. da UFPR - Universidade Federal do Paraná. Departamento de Teoria e Prática de Ensino. E-mail: thais.hilger@gmail.com.
} 
Keywords: Science teaching. Digital Technology. Smartphone. Theory of Meaningful Learning. INTRODUÇÃO

A sociedade submergiu nas tecnologias e deixou o tempo em que a novidade do smartphone e dos computadores era anunciada como a renovação e implementação de novos métodos de trabalho. Antes, o desenvolvimento de novas tecnologias acontecia a cada década e com o passar do tempo diminuiu para anos, meses e atualmente é possível testemunhar constantes desenvolvimentos e o uso das Tecnologias Digitais (TD) nas mais diversas áreas sociais, entre elas a Educação. Essa evolução tecnológica na sociedade já foi, e continua sendo evidenciada por Lévy (2010), o qual afirma que o uso de tecnologias pode modificar as formas do indivíduo se comunicar, pensar e aprender.

Concordando com tal visão, Fuentes (2012, p. Io) afirma que "As tecnologias são muito mais do que meras ferramentas: modificam os ambientes culturais e educativos, criam novos modos de comunicação e reformulam os papéis que as pessoas desempenham habitualmente". Nessa direção, o uso de tecnologias em ambiente educacional pode promover ações distintas das práticas tradicionais de ensino, alterando metodologias e possibilitando uma aprendizagem mais significativa.

Uma das possibilidades de uso pedagógico de TD é o smartphone. Segundo Elias (2018), o uso de smartphones pode possibilitar a aquisição e ampliação de conhecimentos escolares, oportunizando "mobilidade aos usuários, novas possibilidades de comunicação e a ubiquidade. Vale pontuar que o termo ubiquidade está relacionado à possibilidade de estar presente em diferentes espaços 'ao mesmo tempo" (ELIAS, 2018, p. 28).

Diante desses aspectos, presume-se que o uso pedagógico do smartphone pode tornar a aula de Ciências mais atrativa oportunizando formas diferentes de ensinar e de aprender. Nesse viés, propomos como objetivo desta pesquisa verificar como os smartphones estão sendo utilizados no ensino de Ciências dos Anos Iniciais do Ensino Fundamental, em direção a obtenção de uma Aprendizagem Significativa.

Assim, a questão que norteia o trabalho é, de que forma o uso pedagógico de smartphone pode contribuir com o ensino de Ciências nas Séries Iniciais do Ensino Fundamental visando a obtenção de uma Aprendizagem Significativa? Buscando respondê-la, realizamos uma pesquisa qualitativa investigativa por meio de levantamento bibliográfico de pesquisas. 
Nela, visamos informar aspectos quanto a importância do smartphone no processo de ensino e de aprendizagem de Ciências para uma Aprendizagem. Logo, não temos a intenção de analisar tais pesquisas, mas sim apresentar uma síntese dos principais resultados, levantando características alinhadas a temática investigada.

Sendo assim, apresentamos a fundamentação teórica sobre o uso de TD, especificamente os smartphones no Ensino de Ciências. Também, apresentamos uma síntese da Teoria da Aprendizagem Significativa de Ausubel (1999). Na sequência, expomos a metodologia utilizada e os resultados obtidos. Por fim, as nossas considerações finais.

\section{O Uso De Tecnologias Digitais No Ensino De Ciências: Um Olhar Aos Smartphones}

O ensino de Ciências tem sido trabalhado de acordo com diferentes propostas educacionais que aconteceram ao longo das décadas, como elaborações teóricas e pesquisas que, de diversas maneiras, se expressaram no trabalho dos docentes nos ambientes de ensino. Consideramos que muitas das atividades de Ciências são baseadas na mera transmissão de informações, tendo como recurso didático exclusivo o livro e sua transcrição na lousa; outras práticas educativas já incorporam avanços no processo de ensino e aprendizagem sobre o ensino de Ciências. (BRASIL, 1998).

Essas práticas, conforme o decorrer do tempo, podem ser percebidas pelo uso pedagógico de algumas TD, tais como vídeo gravações o computador, a lousa digital, smartphone, entre outros. Nesse movimento, o uso de tais recursos nas aulas de Ciências pode modificar os processos educacionais, rompendo os padrões de aulas tradicionais e/ou laboratoriais.

Conforme apontam Martinho e Pombo (2009), a implementação de recursos tecnológicos no ensino de Ciências proporciona a criação de um ambiente de trabalho mais motivador. Nesse, os alunos podem prender a atenção e ficarem empenhados e rigorosos no desenvolvimento dos seus trabalhos, conseguindo também melhores resultados em termos de avaliação.

Consideramos assim, que as TD se constituem em pontes que abrem a sala de aula para o universo, de qualquer forma, essas, quando combinadas e integradas nos processos educativos, possibilitam uma apreensão da realidade, além de favorecer o desenvolvimento das potencialidades do aprendiz.

Para Mercado, Gomes e Silva (2018) o uso adequado das TD estimula a capacidade de desenvolver estratégias de buscas; transformam não só a maneira de comunicar, mas também a de 
trabalhar, de decidir e de pensar; estimulam o desenvolvimento de habilidades sociais; a qualidade da apresentação escrita das ideias, permitindo autonomia e a criatividade.

Nessa direção, vemos os smartphones como recursos tecnológicos que podem ser utilizados pedagogicamente, oportunizando momentos de dinamismo, criatividade e interação não só de conhecimentos teóricos, mas daqueles relacionados à vida dos estudantes. Logo, cabem olhares quanto ao seu uso visando contribuições ao desenvolvimento dos conteúdos disciplinares.

Estudos como de Santos e Santos (2015) e de Pszybylski (2019) têm demonstrado que o smartphone pode ser considerado como um recurso pedagógico, necessitando, portanto, de uma intervenção adequada por parte dos educadores, capaz de sensibilizar o aluno para a compreensão de sua utilização sob esse enfoque, no contexto da sala de aula. Corroborando com tais pesquisadores, Borba, Silva e Gadanidis (2015) afirmam que o uso de TD em contexto educacional, como os smartphones, propiciam novas dinâmicas e transformação das inteligências coletivas.

Assim, fazer uso do smartphone e de outras TD que estão disponíveis nos ambientes escolares, pode tornar a aula um ambiente investigativo, aguçando a curiosidade, a imaginação e a criatividade dos alunos. Nessa ação o professor está em um movimento de formação (PSZYBYLSKI, 2019), e o aluno, num processo de emancipação e autonomia na construção de seu conhecimento (ELIAS, 2018).

Nesse viés, Santos e Santos (2015) indicam que o acesso às tecnologias móveis, tem proporcionado a estruturação de um novo paradigma educacional, que recebeu o nome de $m$ learning ou aprendizagem móvel, por ser produzida por meio de dispositivos móveis. Essa forma de aprendizagem é resultante de vários projetos de investigação, podendo ser considerada como uma extensão do e-learning. Para Moura (2010), o mobile learning ou m-learning, é caracterizado pela mobilidade da tecnologia.

Isso posto, consideramos o mobile learning como uma forma de aprendizado, podendo ocorrer em qualquer espaço, sendo escolar ou não. Aliado a isso "os smartphones são dispositivos com um grande potencial para a implantação da aprendizagem com mobilidade" (PSZYBYLSKI, 2019, p. 26). Logo, por fazer parte do cotidiano de crianças e adolescentes, além de oferecer diversos recursos e aplicativos, tal recurso precisa contribuir com o bom desenvolvimento da educação (DA SILVA, 2017).

Portanto, é importante que os professores percebam que as TD podem auxiliar em momentos de acesso ao conhecimento. Desse modo, além de aprender sobre o uso das tecnologias, os professores também podem repensar a sua prática pedagógica a fim de ofertar uma melhoria na 
qualidade de ensino e promover o desenvolvimento do aprendiz como indivíduo consciente dos seus direitos e deveres sociais. De acordo com Moran (2007, p. 162-I66), é necessário.

[...] estabelecer pontos efetivos entre educadores e meios de comunicação. Educar os professores para que, junto com seus alunos, compreendam melhor o fascinante processo de troca. Educar para compreender melhor seu significado dentro da nossa sociedade, para ajudar na sua democratização onde cada pessoa possa exercer integralmente a sua cidadania.

Para Mercado, Gomes e Silva (2018) novas formas de aprender e novas competências são exigidas por causa do avanço das tecnologias. Nesse contexto de mudança, cabe ao professor orientar os aprendizes sobre de que forma sondar e colher informações, como tratá-las e como utilizá-las nos ambientes de ensino, tornando-se um mediador da aprendizagem. Assim, a maneira de realizar o trabalho pedagógico também se transforma, sendo necessário ao professor buscar aperfeiçoamento constante para uso das TD.

Desse modo, considerando os diversos meios de ensinar e de aprender que as tecnologias oferecem, especificamente, os smartphones, tais processos deixam de ocorrer prioritariamente no contexto real da sala de aula e passam a ser ofertados em outros espaços e tempos, o que Santaella (1983) denomina por uma aprendizagem ubíqua. Em razão disso, o professor tem um papel essencial para aliar ao seu planejamento ações que promovam o uso de TD visando explorar um determinado conteúdo de Ciências.

Aderir aos avanços tecnológicos existentes e incluí-los na educação, significa que o professor deve investir em si próprio e possibilitar aos seus alunos o acesso à informação e ao conhecimento, transformando-o e permitindo que ele próprio seja o agente transformador de histórias.

\section{Teoria Da Aprendizagem Significativa}

Aprendizagem Significativa é o termo central utilizado na teoria cognitivista desenvolvida por Ausubel entre 1968 e 1980 (MOREIRA, 20II). Este pesquisador, está entre os teóricos que se voltaram ao estudo dos processos de cognição humana, os quais dão sentido e significado. A aprendizagem é um desses processos cognitivos, em que o indivíduo dá significado ao universo ao seu redor enquanto aprende (BESSA, 2008).

O princípio norteador da TAS - Teoria da Aprendizagem Significativa, baseia-se na ideia de que, para que ocorra a aprendizagem nos aprendizes, é necessário partir daquilo que o aluno já 
sabe. Assim, o Ausubel preconiza que os professores devem criar situações didáticas com a finalidade de descobrir os conhecimentos que foram designados por ele como conhecimentos prévios.

De acordo com Moreira (2012), introdutor da TAS no Brasil, o que caracteriza a Aprendizagem Significativa é a interação entre conhecimentos prévios e conhecimentos novos, de modo que a interação tenha caráter não-literal, que não seja ao pé da letra, e não-arbitrária, mas que a interação ocorra com algum conhecimento relevante já existente na estrutura cognitiva do indivíduo.

Dessa forma, a Aprendizagem Significativa pode ser entendida como a ancoragem de informações novas ou os novos conhecimentos estejam apoiados com um aspecto relevante, existente na estrutura cognitiva de cada aprendiz.

Os conhecimentos prévios ou proposições relevantes, que são utilizados dentro da cognição humana para ancorar os novos conhecimentos, são denominados de conhecimentos subsunçores, ideias-âncoras ou apenas subsunçores (MOREIRA, 2012).

De acordo com Bessa (2008), os subsunçores agem como elementos facilitadores do processo de aprendizagem, além dos conhecimentos previamente adquiridos, poderiam ser considerados como subsunçores, os diversos artifícios utilizados durante uma aula para auxiliar na organização do conteúdo, tais como: explicações introdutórias, materiais, atividades voltadas à construção de uma ideia inicial, ou seja, tudo o que possa servir para facilitar a aprendizagem, inclusive a utilização das Tecnologias em sala de aula.

Para Moreira (2012), o processo de interação entre novos e prévios conhecimentos é contínuo, o que causa a modificação das ideias-âncoras, tornando a rede de cognição mais robusta e elaborada. Assim, a Aprendizagem Significativa está relacionada com os conhecimentos prévios e as experiências vividas pelos aprendizes durante seu processo de aprendizagem escolar.

Segundo Moreira (1999) o papel de um professor a princípio é determinar os conhecimentos prévios dos alunos para promover Aprendizagem Significativa. Buscar conhecer o que o aluno já sabe; determinar, dentre os subsunçores, especificamente relevantes (previamente identificados ao "mapear" e organizar a matéria de ensino), quais os que estão disponíveis na estrutura cognitiva do aluno.

Assim, para iniciar um novo conteúdo, pode ser realizado um pré-teste como um diagnóstico dos saberes prévios é viável, porque permite a identificação dos conhecimentos prévios 
do aluno sobre o tema que será abordado, proporcionando um direcionamento das atividades que serão desenvolvidas. No entanto, quando não existem subsunçores para o determinado assunto na estrutura cognitiva do aluno, promove-se uma estratégia de aquisição de conceitos, baseada em organizadores prévios que:

[...] são materiais introdutórios apresentados antes do material de aprendizagem em si, em um nível maior de abstração, generalidade e inclusividade. Sua principal função é a de servir de ponte entre o que o aprendiz já sabe e o que ele deve saber a fim de que o novo material possa ser aprendido de maneira significativa. (MOREIRA,I999, p. 36)

A aprendizagem pode ser considerada significativa quando novos conhecimentos, conceitos, ideias, proposições, passam a ter significado para o aprendiz. Ou seja, quando ele é capaz de explicar com suas próprias palavras o conteúdo aprendido e quando resolve problemas que surgem por si mesmo.

\section{METODOLOGIA}

A pesquisa realizada assume uma abordagem qualitativa do tipo exploratória. Segundo Denzin e Lincoln (2006, p.32) a "pesquisa qualitativa é caracterizada como uma pesquisa que enfatiza a qualidade das entidades e dos processos que não são examinadas por medidas de quantidade, volume ou frequência".

Neste seguimento, Gil (2005) destaca que a pesquisa exploratória costuma envolver levantamento bibliográfico; entrevistas com sujeitos da pesquisa e análise de exemplos que estimulem a compreensão quanto ao assunto investigado.

Isso posto, realizamos um levantamento de pesquisas que tratam sobre o tema investigado. Para isso escolhemos o banco de dados a Biblioteca Digital Brasileira de Teses e Dissertações (BDTD). Informamos que a pesquisa foi realizada entre a última semana do mês de janeiro até a segunda semana de fevereiro de 2021.

Como recorte temporal, buscamos selecionar apenas as dissertações no período de 2018 a 2020. Escolhemos tal período pois objetivamos observar estudos atuais que possam orientar caminhos quanto ao uso do smartphone no ensino de Ciências nos Anos Iniciais do Ensino Fundamental. Assim, no levantamento de dados, foi utilizado combinações dos descritores, como, "Ensino de Ciências" AND “Tecnologia” AND "Aprendizagem Significativa”, Ensino de 
Ciências" AND "Celular" AND "aprendizagem significativa", "Ensino de Ciências" AND "Celular" AND "Anos Iniciais", "Tecnologia” AND "Ensino de Ciências" AND "Anos Inicias".

Dessa sondagem, tivemos um retorno de 67 pesquisas. A Tabela i expõe o total de resultados encontrados na BDTD para cada descritor.

Tabela I - Levantamento de Dissertações sobre o uso de Celulares para o Ensino de Ciências nos anos iniciais no período de 2018 a 2020 .

Descritores

Quantidade de pesquisas levantadas

\section{Quantidade de} pesquisas selecionadas

\begin{tabular}{|c|c|c|}
\hline $\begin{array}{l}\text { "Ensino de Ciências" AND “Tecnologia" } \\
\text { AND "Aprendizagem Significativa" }\end{array}$ & 37 & I \\
\hline $\begin{array}{l}\text { "Ensino de Ciências" AND "Celular" } \\
\text { AND "Aprendizagem Significativa" }\end{array}$ & o6 & o \\
\hline $\begin{array}{l}\text { "Ensino de Ciências" AND "Celular" } \\
\text { AND "Anos Iniciais" }\end{array}$ & o & o \\
\hline $\begin{array}{l}\text { "Ciências" AND "celular" AND "Anos } \\
\text { Iniciais" }\end{array}$ & 2 & I \\
\hline $\begin{array}{l}\text { Tecnologia" AND "Ensino de Ciências" } \\
\text { AND "Anos Inicias" }\end{array}$ & 22 & I \\
\hline TOTAL & 67 & 3 \\
\hline
\end{tabular}

Fonte: autoria própria

Dessas 67 pesquisas encontradas, foram lidos os títulos e realizada uma leitura completa dos resumos. Nessa ação, observamos às pesquisas que apresentavam aspectos do uso do smartphone no ensino de Ciências, conforme a tabela 2. Posteriormente, identificando àquelas que foram investigadas no Ensino fundamental Anos Iniciais e que possuíam uma interface com a Aprendizagem Significativa. Após tal ação, resultaram apenas três dissertações que se adequavam ao nosso objeto de estudo. 
Tabela 2 - Dissertações com aspectos do uso do Smartphone em Ciências.

\begin{tabular}{|c|c|c|}
\hline Dissertação & Autor e Ano de defesa & Instituição \\
\hline $\begin{array}{l}\text { Possibilidades de Utilização de } \\
\text { Smartphones em Sala de aula: } \\
\text { Construindo Aplicativos } \\
\text { Investigativos Para o Trabalho com } \\
\text { Equações no 2o Grau. }\end{array}$ & $\begin{array}{l}\text { Elias, Ana Paula de } \\
\text { Andrade Janz } \\
\text { (2018) }\end{array}$ & $\begin{array}{c}\text { UTFPR } \\
\text { Campus Curitiba }\end{array}$ \\
\hline $\begin{array}{l}\text { Uso de Tecnologias Digitais de } \\
\text { Informação e Comunicação no } \\
\text { Ensino de Ciências e Biologia. }\end{array}$ & $\begin{array}{c}\text { Damasceno, Maria Sousa } \\
\text { Manoel } \\
(2019)\end{array}$ & $\begin{array}{c}\text { Universidade } \\
\text { Federal do Espirito } \\
\text { Santo - UFES } \\
\text { Campus São Mateus }\end{array}$ \\
\hline $\begin{array}{l}\text { Ciência e Tecnologias nos Anos } \\
\text { Iniciais da Rede Municipal de } \\
\text { Ensino de Curitiba: Compreensões } \\
\text { Curriculares Para a Prática Docente }\end{array}$ & $\begin{array}{c}\text { Simeão, Manuelle Pereira } \\
\text { da Costa } \\
(2019)\end{array}$ & $\begin{array}{c}\text { UTFPR } \\
\text { Campus Curitiba }\end{array}$ \\
\hline TOTAL & 3 & \\
\hline
\end{tabular}

Fonte: autoria própria

A dissertação de Elias (2018), no Programa de Pós-Graduação em Formação Científica, Educacional e Tecnológica da Universidade Tecnológica Federal do Paraná (UTFPR), campus de Curitiba, trata das contribuições de utilização de smartphones, por meio da criação, no software App Inventor, e validação de aplicativos matemáticos educativos para o ensino de equações do segundo grau. O foco da pesquisa de Elias (2018) traz o uso do celular para o ensino de matemática aplicado ao Ensino Médio e não aos Anos Iniciais do Ensino Fundamental, logo a mesma foi excluída de nossa investigação.

Portanto, nesse procedimento de exclusão, restaram apenas duas dissertações, a de Damasceno (2019) e a de Simeão (2019). Destas, realizamos o fichamento buscando observar de que forma ocorreu o uso de smartphone no ensino de Ciências, direcionado ao Ensino Fundamental I e a forma como a Aprendizagem Significativa ocorreu no estudo. $\mathrm{Na}$ sequência, apresentamos ambos os trabalhos e nossa síntese compreensiva sobre elas.

\section{Pesquisas Levantadas E Síntese Compreensiva Do Estudo}


Nesse momento, apresentamos as pesquisas de Damasceno (2019) e Simeão (2019), destacando os itens: programa de pós-graduação onde foi realizado o curso e defendida a dissertação, objetivo do estudo/pesquisa, pergunta norteadora, público investigado, conclusão do autor. Informamos que nossa intenção não é de analisar tais estudos, mas sim destacar aspectos que possam atender ao nosso objetivo proposto.

A pesquisa de Damasceno (2019) foi apresentada ao Programa de Pós-Graduação em Ensino na Educação Básica (PPGEEB) da Universidade Federal do Espírito Santo, Campus São Mateus. Tinha como objetivo, analisar a utilização, limitação e potencialidade do smartphone como uma TD, para o ensino de Ciências e Biologia nas escolas da rede pública do Norte do Espírito Santo.

O pesquisador frisa o quanto é importante trabalhar com a tecnologia em sala de aula, pois, possibilita novas formas de ensinar conteúdos que muitas vezes são explorados somente por meio do livro didático. Para o autor, "Novidades nas salas de aula, como as TDICs, motivam os alunos e estes, quando motivados, se interessam mais pelo conteúdo, produzem mais e consequentemente conseguem um aprendizado mais elevado" (DAMASCENO, 2019, p.33).

O trabalho apresenta compreensões de como se dá o uso de materiais tecnológicos pelos professores de Ciências e Biologia, analisando o entendimento desses acerca do uso de smartphone, suas limitações, preocupações, consequências e potencialidades para o ensino dos conteúdos.

Para isso, utilizou três etapas de trabalho: $\mathrm{Na}$ primeira, inicialmente a pesquisadora criou um roteiro de entrevistas semiestruturadas para professores, mas, teve a dificuldade em obter autorização das escolas para a realização da pesquisa e a disponibilidade dos educadores para realização das entrevistas.

Frente a isso, a pesquisadora idealizou um questionário online de múltipla escolha e enviou o link de acesso a 13 professores, porém, a pesquisadora só obteve retorno de cinco questionários respondidos.

Mediante esse questionário, buscou sondar se a escola oferecia equipamentos tecnológicos para os professores utilizarem em seus trabalhos em sala de aula e se os educadores utilizavam celulares, ou computadores, para preparar e ministrar suas aulas.

Diante da questão, a pesquisadora, verificou que as escolas não estavam preparadas e não formavam os profissionais da educação para trabalhar com as TD em sala de aula e, constata ainda 
que, "Muitos professores ainda são resistentes ao uso delas; a maioria dos professores reconhece indícios de Aprendizagem Significativa quando as TDs são usadas” (DAMASCENO, 2019, p. o7).

Como segunda etapa do trabalho, a pesquisadora realizou uma busca por pesquisas que abordavam e discutiam as TD para o ensino de Ciências. Foram encontradas várias possibilidades de recursos tecnológicos como Blogs, Vídeos, Atlas, Jogos e Atividades Digitais, Sites, Aplicativos e Webquests para o trabalho com Ciências.

Para a última etapa, a pesquisadora ministrou aulas durante um mês utilizando algumas $\mathrm{TD}$, com foco no smartphone e as possibilidades de recursos encontrados nele e através dele, para aplicação das atividades. Entre as possibilidades utilizadas através do smartphone, Damasceno (2019, p. 7o), relata sobre os vídeos nas aulas.

"Nas escolas, o interesse dos alunos é maior nas aulas em que vídeos são utilizados, já que tal atividade se apresenta como uma alternativa diferente, geralmente mais atraente e menos exaustiva em relação às aulas expositivas baseadas nos livros didáticos".

Com relação às possibilidades de utilizar em aulas os jogos e atividades digitais por meio do smartphone, Damasceno (2019, p. 8o) relata que.

Além de poder ser utilizado em sala de aula como forma pedagógica, os jogos digitais podem aguçar o interesse do aluno em continuar ou repetir a atividade em casa, buscar novos desafios na internet e divulgar para seu grupo de amigos, o tornando assim mais próximo do conhecimento científico de uma forma natural e descontraída.

Com isso, Damasceno (2019) concluiu que as escolas não estão preparadas com materiais Tecnológicos para os professores trabalharem e ainda, identifica que os professores anseiam por novas TDs para melhorar a prática em sala de aula.

Com a vivência prática em sala de aula, a pesquisadora relata que observou melhoria e evolução no aprendizado dos alunos quando o smartphone foi inserido. Ainda, Damasceno relata: "Foi identificado neles, a aspiração por aulas diferentes, o fascínio pelas imagens e vídeos transmitidos e o interesse em conhecer cada vez mais a Ciência”. (DAMASCENO, 2019, p. 102).

Direcionando olhares à pesquisa de Simeão (2019), esta foi apresentada ao Programa de Pós-Graduação em Formação Científica, Educacional e Tecnológica (PPGFCET), da Universidade Tecnológica Federal do Paraná (UTFPR). Teve como objetivo, compreender as práticas de Ciência e Tecnologia desenvolvidas com os Anos Iniciais do Ensino Fundamental, em escolas de tempo 
integral da Rede Municipal de Ensino de Curitiba. Expôs como pergunta: "O que é isto, o Ensino de Ciência e Tecnologias nos anos iniciais do Ensino Fundamental"? O trabalho da pesquisadora destinava-se a realizar uma análise por meio do que vinha explícito nos documentos que orientam a ação docente de Curitiba.

A pesquisadora traz variáveis caminhos a percorrer para chegar a uma conclusão da investigação, entre eles, buscar aspectos da história da prática, no contexto da educação integral, as políticas públicas que viabilizaram a construção de documentos que orientam o contexto da educação integral.

Entre os documentos que Simeão utilizou para fundamentar a questão de pesquisa e investigação, estão o Caderno Pedagógico de Educação Integral e o Caderno de Subsídios para a organização de práticas educativas em oficinas nas unidades escolares com oferta de educação em tempo integral. Também fez a utilização de pesquisas já realizadas, manifestos na academia sobre ensino de ciência e tecnologia nos anos iniciais.

Ao analisar o Caderno Pedagógico de Educação Integral, Simeão (2019, p. 6o) relata o seguinte:

$\mathrm{Na}$ leitura do referido caderno, à luz da interrogação, mostraram-se em destaque sete ideias centrais para o ensino que contemple a formação científica e tecnológica do aluno: CTS; Produção e Socialização do Conhecimento Científico; Educação Científica e Tecnológica; Concepção de Tecnologia; Ensino da Prática CT; Concepção de Ciência e Pensamento Científico.

Ainda, com referência a análise feita no Caderno Pedagógico, Simeão (2019, p. 37-38) diz que

[...] existe uma intenção de proporcionar novas abordagens para o ensino, utilizando, por exemplo, o smartphone em sala de aula como um recurso que apresenta diversas possibilidades de aplicativos para complementar o ensino e, através do uso consciente, chegar a uma alfabetização científica e tecnológica que cultive, ainda nos anos iniciais, cidadãos conscientes do papel da ciência e da tecnologia na sociedade, bem como uma educação que proporcione um posicionamento crítico e uma tomada de decisão frente a situações enfrentadas no seu cotidiano.

Acerca da conclusão, a pesquisadora elaborou um material de estudo e reflexão, um caderno formativo direcionado aos professores que trabalham com as Práticas de Ciência e Tecnologia dos Anos Iniciais do Ensino Fundamental. O intuito do material formativo elaborado não era de trazer planos de aulas de Ciências prontos para serem utilizados, mas oportunizar aos 
professores, por meio de leituras, novas práticas em sala de aula, utilizando-se de tecnologias disponíveis principalmente o smartphone para a condução de atividades.

O caderno formativo elaborado pela pesquisadora, traz como foco o Ensino de Ciência e Tecnologias com vistas ao smartphone e, de práticas pedagógicas que contribuíssem com o enfrentamento da alfabetização científica e tecnológica das crianças, vislumbrando possibilidades para pensar a formação docente dos educadores de Ciências.

Mediante tais estudos, observamos que a utilização de smartphones no processo de ensino de Ciências do Ensino Fundamental I, direcionam olhares quanto a importância do papel do professor em se informar e utilizar pedagogicamente tal recurso. Nesse movimento, a formação continuada é um tema pertinente quanto a complementação de estudos e práticas na área profissional do docente.

Isso posto, a pesquisa busca e evidencia em documentos educacionais oficiais, a necessidade de trazer para a formação docente possibilidades do ensino de Ciências que enlacem a perspectiva da construção do conhecimento científico. Nessa orientação, tendo o enfoque Ciência, Tecnologia e Sociedade (CTS) bem como nos pressupostos da Alfabetização Científica e Tecnológica.

Quanto ao processo de aprendizagem, notamos que os estudos destacam que os alunos, ao interagirem com smartphones para exploração de conteúdos de Ciências, mostram-se motivados e se engajam na proposta da atividade. Nesse meio, pode haver a construção da Aprendizagem Significativa.

Sendo a TAS, assim como em outras teorias de base cognitivista, prioriza como conceito central o processo pelo qual uma nova informação se relaciona, com os conhecimentos relevantes preexistentes na estrutura cognitiva do aluno. Também está relacionada com os conhecimentos prévios e as experiências vividas pelos aprendizes durante o seu processo de aprendizagem escolar que podem atuar como pontos de ancoragem de novas ideias.

Ainda, os pesquisadores destacam que os alunos vivenciam experiências diferentes quando utilizam alguma TD. Que mediante exploração dessas, levantam hipóteses, discussões e buscam por conhecimentos. Diante disso, a aprendizagem pode tornar-se significativa e promover transformações cognitivas.

Por fim, Damasceno (2019) e Simeão (2019) alertam que as escolas não estão preparadas e não preparam os seus profissionais para lidar com TD. Os prováveis motivos condizem com a 
resistência dos professores ao uso delas, porém, a maioria dos docentes participantes da pesquisa, reconhece uma Aprendizagem Significativa quando as tecnologias são usadas.

Essas indicações apresentadas, são realizadas através dessa pesquisa usando o banco de dados BDTD, porém, em casos de mudanças de descritores no momento da busca no banco de dados ou, utilizado outros bancos de dados disponíveis, consideramos que podem surgir outros estudos com a temática e conclusões diferentes.

\section{CONSIDERAÇÕES FINAIS}

Este trabalho teve como objetivo verificar como os smartphones estão sendo utilizados no ensino de Ciências dos Anos Iniciais do Ensino Fundamental, em direção a obtenção de Aprendizagem Significativa. Para isso, realizamos uma pesquisa qualitativa por meio de levantamento de pesquisas.

Nesse processo recorremos a BDTD, e após aplicados descritores, obtivemos o retorno de 67 pesquisas que abordavam o uso de TD no Ensino de Ciências. Após critérios de exclusão e inclusão, resultaram duas pesquisas que tratavam do uso do smartphone no ensino de Ciências.

Dessas, destacamos que o uso pedagógico de smartphones pode possibilitar um ambiente investigativo, modificando os processos de ensino e de aprendizagem de Ciências. Logo, tanto professores quanto alunos podem se beneficiar dessas tecnologias e usá-las em benefício educacional. Os professores, visando sua formação profissional e compartilhamento de conhecimentos aos demais colegas e alunos, já os alunos podem estar fazendo uso de uma ferramenta habitual do dia a dia e empregá-la para a construção do conhecimento.

Nesse movimento, compreendemos que os smartphones estão presentes no meio educacional e cabe aos professores utilizar em suas práticas pedagógicas. Para tanto, os professores devem buscar capacitação para compreensão e uso correto nas aulas.

Quanto ao processo de aprendizagem, a exploração dessas tecnologias no contexto educacional, possibilita que o aluno explore um material diferente do tradicional (caderno e livro). Nesse contexto, pode-se ter contato com aplicativos que possibilitam manipulação e simulação que os direcionem pela busca do conhecimento, podendo implicar numa aprendizagem significativa. Assim, podem rever conceitos, promover novas investigações e tomadas de decisões.

Nesse contexto, resgatando nossa pergunta investigativa: de que forma o uso pedagógico de smartphone pode contribuir com o ensino de Ciências nas séries iniciais do ensino fundamental visando a Aprendizagem Significativa? Observando os estudos, podemos afirmar que para que haja 
contribuições nos processos de ensino e de aprendizagem de Ciências, no viés da Aprendizagem Significativa, os smartphones devem ser utilizados aliados a um conteúdo curricular específico e abordando o contexto educacional dos envolvidos.

Portanto, cabe ao professor buscar conhecimentos de como utilizá-lo de forma pedagógica, para isso recomendamos cursos de formação, cabe ao aluno o uso consciente de tal tecnologia, interagindo com o propósito de sondar um material escolar em prol da construção do conhecimento.

Assim, a utilização de TD, como o smartphone, nos ambientes escolares, torna-se uma necessidade imediata diante das mudanças que vêm ocorrendo na sociedade da informação. Essa necessidade não vem para substituir quadro, livro didático, giz ou pincel, mas como possibilidade de aplicar TD como recursos de ensino diferenciado e contribuindo para uma Aprendizagem Significativa nos aprendizes inseridos na era digital.

Por fim, visto que são poucas as dissertações/teses atuais sobre o uso de smartphones no ensino de Ciências para os Anos Iniciais, sugerimos a continuação de estudos baseados na utilização do smartphone no ensino de Ciências como um recurso tecnológico que possa promover mudanças de pensamentos e aprendizagens.

\section{REFERÊNCIAS}

AUSUBEL, D., P. Aquisição e retenção de conhecimentos: uma perspectiva cognitiva. Lisboa: Plátano, 2003.

BACICH, Lilian. Ensino Híbrido Personalização e Tecnologia na Educação. Porto Alegre: Penso, 2015 .

BATISTA, Cláudia Regina (Orgs). Hipermídia e interdisciplinaridade na geração de conhecimento. São Paulo: Pimenta cultural, 2015.

BERBEL, N. A. N. As metodologias Ativas e a Promoção da Autonomia de estudantes. Semina: Ciências Sociais e Humanas, vol. 32, n. I, p. 25-40, 2011.

BORBA, M. C.; DA SILVA, R. S. R.; GADANIDIS, G. Fases das Tecnologias Digitais em

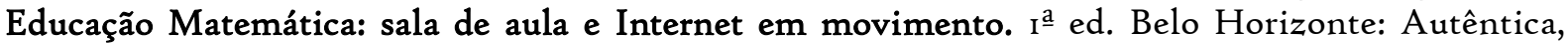
2015 .

BDTD. Biblioteca Digital Brasileira de Teses e Dissertações. Acesso em: 17 de fevereiro. 202I. 
BRASIL. Ministério da Educação, Secretaria de Educação Média e tecnológica. Parâmetros Curriculares Nacionais: Ensino Médio. Brasília: Ministério da Educação, 1999.

BRASIL. Ministério da Educação. Secretaria de Educação Fundamental. Parâmetros Curriculares Nacionais: Ciências Naturais. ( $3^{\circ}$ e $4^{\circ}$ ciclos do ensino fundamental). Brasília: MEC, 1998.

\section{BNCC - TECNOLOGIAS DIGITAIS DA INFORMAÇÃO E COMUNICAÇÃO NO CONTEXTO ESCOLAR: POSSIBILIDADES. Disponivel em:}

http://basenacionalcomum.mec.gov.br/implementacao/praticas/caderno-de praticas/aprofundamentos/193-tecnologias-digitais-da-informacao-e-comunicacao-no-contextoescolar-possibilidades. Acesso em: I9 de janeiro de 2021.

CLARO, Paulo César Gastaldo. Mídias e Educação: outros diálogos. ${ }^{\underline{a}}$ ed. Rondônia: Clube dos Autores, 2013.

DA SILVA, J. M. Novas tecnologias em sala de aula. Revista ciencia, salud, educación y economia n. II, p. 32, 2017.

DOS SANTOS, J. O.; SANTOS, R. M. S. O uso do celular como ferramenta de aprendizagem. Revista Brasileira de Educação e Saúde, v. 4, n. 4, p. I-6, 2015. Disponível em: http://gvaa.com.br/revista/index.php/REBES/article/view/3108/2596. Acesso em: I3 abril, 2021.

ELIAS, A. P. A. J. Possibilidades de utilização de smartphones em sala de aula: construindo aplicativos investigativos para o trabalho com equações do $2^{\circ}$ grau. 2018. $135 \mathrm{f}$. Dissertação (Mestrado em Formação Científica, Educacional e Tecnológica) - Universidade Tecnológica Federal do Paraná, Curitiba, 2018.

FUENTES, S. S. O porquê e o como das ciências na educação infantil. Pátio -Ciências na educação infantil, Porto Alegre. Ano X, n. 33, p.o8-II. Out/dez, 2012.

GEBRAN, Maurício Pessoa. Tecnologias Educacionais. Curitiba: IESDE Brasil S.A., 2009.

GIL, A. C. Metodologia do Ensino Superior. 4. ed. São Paulo: Atlas, 2005.

KENSKI, V. M., Educação e tecnologias: $\mathrm{O}$ novo ritmo da informação. $2^{\underline{a}}$ ed. Campinas, SP: Papirus, 2007, p. 46

KRASILCHIK, M.; Reformas e realidade o caso do ensino das ciências. São Paulo em perspectiva, v. I4, n. I, 2000.

LÉVY, P. As tecnologias da inteligência: o futuro do pensamento na era da informática. São Paulo: Editora 34, 2 ed., 2010.

MARTINHO, Tânia; POMBO Lúcia. Potencialidades das TIC em ensino das ciências naturais um estudo de caso. In: Revista electrónica de enseñanza de las ciências, v. 8, n. 2. 2009. 528 p. Disponível em: http://reec.uvigo.es/volumenes/volumen8/ART8_Vol8_N2.pdf. Acesso em: is abril. 2021. 
MERCADO, Luis Paulo Leopoldo; GOMES Maria Gisélia Silva; SILVA Carla Glycia Santos. Metodologia Do Ensino Superior Com Tecnologias Da Informação E Comunicação:Estratégias De Ensino Experienciadas. V.2, n. 2. 2018. p. 453 - 478. maio/ago. 2018. Disponível em: https://periodicos.ufv.br/educacaoemperspectiva/article/view/7049/2862. Acesso em: is abril. 2021.

MOURA, A.M.C. Apropriação do Telemóvel como Ferramenta de Mediação em Mobile Learning: Estudos de Caso em Contexto Educativo. 20I0. Tese (Doutorado em Ciências da Educação) Universidade do Minho. Braga, 2010.

MORAN, J. M. As mídias na educação. In: MORAN, J, M. Desafios na comunicação Pessoal. $3^{\text {a }}$ Ed. S.P.: Paulinas, 2007, p. 162-166.

MOREIRA, M. A. Aprendizagem Significativa. Primeira Edição. Brasília: Editora Universidade de Brasília, i999b.

ORTEGA, Angel Cobo; VANTI, Adolfo. Gobernanza Empresarial de Tecnologías de la Información. Santander: Editorial de la Universidad de Cantabria D.L., 2015.

PSZYBYLSKI, Rafael Felipe. O uso do software de programação App inventor 2 na formação inicial de professores de ciências. 2019. Dissertação (Mestrado em Formação Científica, Educacional e Tecnológica) - Universidade Tecnológica Federal do Paraná, Curitiba, 2019.

SANTAELLA, Lúcia. O que é semiótica. São Paulo: Editora Brasiliense, Coleção Primeiros Passos, 1983.

SARTORI, A. S.; SOARES, M. S.; Concepção dialógica e as NTICs: A Educomunicação e os ecossistemas Comunicativos. V Colóquio Internacional Paulo Freire, Recife, 2005.

SIMEÃO, Manuelle Pereira da Costa. Ciência e tecnologias nos anos iniciais da Rede Municipal de Ensino de Curitiba: compreensões curriculares para a prática docente. Pgs. 131. Dissertação defendida no Programa de Pós-Graduação em Formação Científica, Educacional e Tecnológica (PPGFCET), da Universidade Tecnológica Federal do Paraná (UTFPR). Disponível em: CT_PPGFCET_M_Simeão, Manuelle Pereira da Costa_2019.pdf. Acesso em: I8 de fevereiro de 2021. 